\title{
Frequency and Risk Factors Associated with Mortality in Pregnant Women in Tehran-Iran
}

\author{
Fereshteh Farzianpour ${ }^{1}$, Khatere Ramezani ${ }^{1}$, Najmeh Bahmanziari ${ }^{1}$ \& Omolbanin Atashbahar ${ }^{1}$ \\ ${ }^{1}$ Department of Health Management and Economics, School of Public Health, Tehran University of Medical \\ Sciences, Tehran, Iran \\ Correspondence: Fereshteh Farzianpour, Department of Health Management and Economics, School of Public \\ Health, Tehran University of Medical Sciences, Tehran, Iran. E-mail: farzianp@sina.tums.ac.ir
}

$\begin{array}{lc}\text { Received: January 20, } 2016 & \text { Accepted: February 7, } 2016 \quad \text { Online Published: July 11, } 2016 \\ \text { doi:10.5539/gjhs.v9n3p138 } & \text { URL: http://dx.doi.org/10.5539/gjhs.v9n3p138 }\end{array}$

\begin{abstract}
Background and Objectives: Ending mortality in pregnant women is not just a health challenge, but a development challenge. The purpose of this study was to access the frequency and risk factors associated with maternal mortality in Tehran from 2008 to 2011.

Methods: The present study was a case-control study with a population group which consists of all the women who have died since the beginning of pregnancy up to 42 days after delivery from the year 2008 to 2011 and a control group which consists of all delivered pregnant women with a perfect record in the hospitals $(n=16)$ in Tehran from 2008 to 2011. In the case group, sampling was done through census $(n=113)$ and random sampling was used in the control group and 327 people were selected. Data collection tool was a record sheet consisting of two parts: demographic and risk factors associated with pregnancy which was completed using the data in the case and control groups. Finally, SPSS 22, descriptive statistics and statistical tests such as Chi-square, t-test and Fisher were used to analyze the data.
\end{abstract}

Results: Maternal deaths were reported in Tehran from 2008 to 2011 and the ratio was 15.8 in 100 thousand of live births during the period. Among the mothers who died, $73.5 \%$ of them were 18 to 34 years old, $1.22 \%$ were 35 years old or above and only $4.4 \%$ were less than 18 years of age. Of these mothers that died, $83.2 \%$ lived in the city and $16.8 \%$ lived in rural areas, but there were significant relationship between age, place of residence and maternal deaths. In combination with other risk factors, such as pregnancy age, pregnancy number, number of abortions, underlying medical condition, access to appropriate prenatal care, methods of delivery, factors of delivery, and the time may be between two last pregnancy, a significant difference was observed between the case and control groups, except for the distance between the two last pregnancy.

Conclusion: Maternal mortality has been declining over the years; due to the identified factors associated with maternal death, proposed strategies, such as improving the quality of hospital services in the field of obstetric emergencies, improving the quality and coverage of prenatal care, avoidance of selective cesarean sections, identifying high risk pregnancies and referrals to specialized centers.

Keywords: frequency, risk factors, maternal, women

\section{Background}

The World Health Organization (WHO) in version 10 of International Classification of Diseases (ICD-10) defined maternal mortality as maternal death during pregnancy or within $24 \mathrm{~h}$ after delivery irrespective of the duration and place of delivery from any cause related to pregnancy or aggravated by the pregnancy or its management. This definition does not include the causes of accidents and incidents (Fight against Diseases for Nurses, 2006). Ending maternal mortality is not only a health challenge, but a development challenge.

Today, it is clear that healthy mothers will not only help in the global health goals, but will also help in the completion of a wide range of development goals in promoting economic growth and increasing food security, peace and the establishment of democratic countries (Abdollahpour et al., 2011). Considering the existence of resources, knowledge and resources with the collective effort of the international community and a strong political commitment, can finish the preventable maternal death in a generation.

Accepting this goal as international goal reflects the attention to a common goal among the rich and poor nations 
that reduces the maternal mortality in the world, on average, less than 70 cases per hundred thousand live births by 2030 and less than 50 cases per hundred thousand live births is 2035 (Imami Afshar Nehzat et al., 2010).

Strategies that can help us achieve this goal include improving the norms and behaviors of individual, family and community, improving equity in access and use of services by vulnerable groups, strengthening the cohesion of family planning and maternal health services, quality measurement of mother and child health care, prevention, diagnosis and treatment of indirect causes of maternal mortality and poor outcomes for pregnant women, increasing focus on preventing and dealing with pregnancy-related complications and disabilities, strengthening and supporting health systems, promoting innovation and research for planning and policy-making, improving information for decision-making and accountability, improving choice right and care with respect to mothers and improving working conditions for providers (Imami Afshar Nehzat et al., 2010).

Preventable maternal mortality remained an unfinished agenda and one of the most critical global challenges despite the progress achieved in reducing maternal mortality in the past decade (Maternal Health Department of Family Health and Population, 2011). In evidence, 289 million women around the world lose their lives as a result of pregnancy and childbirth. Most of these women live in poor countries where there are wide disparities (Maternal Health Department of Family Health and Population, 2010). The most common cause of maternal death in 2011 in Iran as reported. In 60 to 80 percent, maternal deaths are due to hemorrhage, hard labor, high blood pressure, infections and Complications of Unsafe abortions, noticeable percent of which occur after childbirth and about 78 percent of it is related to 24 to 48 first hours after childbirth, preeclampsia and eclampsia (23\%) and bleeding (20.4\%) (Farzianpour et al., 2014).

Women should not encounter unequal risk of death and disability due to pregnancy and childbirth for living location (Maternal Health Department of Family Health and Population, 2011 .But wide disparities exist among different countries. Also, there are inequalities within countries between people with high and low income and between urban and rural residents (Mohammadinia et al., 2013).

Amnesty international organization also focused on the disease and maternal mortality and the human rights center. As reported on the 12 March 2010, the fatal childbirth claimed that this case is not only a public health problem, but a human rights issue (Rajaei et al., 2013), so preventable maternal mortality could reflect different things, like human rights, including the right to life, right to freedom from discrimination and right to the highest attainable standard of health.

Governments are required to respect these rights and other human rights and to fulfill it and finally make responsible health systems to meet all these rights to ensure fairness and universality (Jamshedpur et al., 2014) All women need prenatal care during pregnancy, childbirth and professional care and support during the weeks after birth. It is especially important that all surgeries be done by qualified personnel who have enough skills. Management and treatment can make a difference between life and death (Mohammadinia et al., 2013).

The World Health Organization divided the causes of maternal mortality into both direct and indirect causes. Direct causes can be due to pregnancy complications and failure, while indirect causes of maternal mortality in developing countries are due to HIV, malaria and tuberculosis (Golian et al., 2002). Since the determination of the causes and risk factors for maternal mortality is the prerequisite for the implementation of any program to reduce maternal mortality, several studies have been conducted in the field of causes of maternal mortality.

Evence et al. (2013) in their study noted bleeding, infection and preeclampsia as the main causes of maternal mortality in rural regions of Tanzania (Office of Family Health and Population, IMES, 2005) Hernández-Correa (2010) in this study suggests that maternal mortality in Madagascar in addition to the social variables have been related to age, educational level of women and the presence of underlying disease, such as malaria and tuberculosis (Golian et al., 2004)

Also, Iqbal et al. (2014) showed that the most causes of maternal mortality in Guinea are direct reasons, such as bleeding, hypertensive disorders in pregnancy and infection (Abdolmohammad Khajehian et al., 2011). Research findings of Hosseini (2006) showed that a large number of deaths in women occurs immediately after delivery and early postpartum (GholamiTaramsari Mahshid, 2008).

Abdollahpour et al. (2012) in their study in Ilam province introduced bleeding as the major cause of maternal mortality (Arshin Chi, 2009). EmamiAfshar et al. (2009) in a study noted the cause of maternal deaths as bleeding, hard labor, high blood pressure, infections and complications of unsafe abortion in 60 to $80 \%$ of cases (Mansouri et al., 2005).

According to the latest report of WHO, the Islamic Republic of Iran is introduced as one of the most successful countries in achieving the fifth goals of Millennium Development. Although publication of this report is 
considered a significant success, but to maintain and improve this index, it will be very difficult and require more effort and implementation of interventions beyond the existing programs (Alkema et al., 2014). Also, the evaluation of index process based on the ratio of maternal mortality data showed lower maternal mortality or relative stability in this indicator, particularly in recent years (Miller et al., 2015).

Given the importance of identifying the causes, prevention and the need to continue the process of reducing the maternal mortality ratio, this study was conducted to access the frequency and risk factors associated with maternal mortality in Tehran from 2008 to 2011 to identify and prioritize the factors affecting maternal mortality by presenting the results and providing it to the authorities and planners which took a step to further reduce maternal mortality.

\section{Methods}

The present study is a case-control study. This study was approved by the Ethical Committee of Tehran University of Medical Sciences (TUMS). Study population had two subpopulations. The first was all pregnant women resident in Tehran, Iran. The definition of a death was the occurrence of death from the first time of pregnancy up to 42 days after delivery between year 2008 and year 2011. Second subpopulation was women with same characteristic but alive after delivery in all hospitals $(\mathrm{N}=16)$ in Tehran with the full record.

Sampling of the case group was done by census and all maternal deaths were investigated $(N=113)$. Sample size of the control group was estimated 130 by plugging $\mathrm{p}=0.50$ and $\mathrm{OR}=2.0$ in the following formula and to increase the power of test the sample size in control group was increased by three times so that the control sample increased to 327 people.

$$
\begin{aligned}
& P_{0}=0.5 \\
& O R=2 \\
& P_{1}=\frac{O R \times P_{0}}{1+(O R-1) P_{0}}=\frac{0.5 \times 2}{1+0.5}=0.67 \\
& P=\frac{P_{0}+P}{2}=\frac{0.5+0.67}{2}=0.585 \\
& n=\frac{2\left(z_{1-\frac{\alpha}{2}}+z_{1-\beta}\right)^{2} p(1-p)}{\left(p_{1}-p_{0}\right)^{2}} \\
& n=\frac{2(1.96+0.84) \times 0.585(1-0.585)}{(0.67-0.5)^{2}}=130
\end{aligned}
$$

Data collection tool was a record sheet consisting of two parts: demographic and risk factors associated with pregnancy which was completed using the data in the case and control groups. Finally, SPSS 22 software, descriptive statistics and statistical tests such as Chi-square, t-test and Fisher were used to analyze the data.

\section{Results}

Maternal deaths $(\mathrm{n}=113)$ were reported in Tehran from 2008 to 2011. The ratio of maternal deaths was 15.8 in 100 thousand of live births during this period. The highest maternal mortality ratio was 19.1 in 2009 and the lowest proportion was 13 in 2011. Maternal deaths were considered as a direct effect (complication of pregnancy $23.9 \%$, childbirth $8.8 \%$, postpartum complications $67.3 \%$, eclampsia, pre-eclampsia $23 \%$, bleeding $20.4 \%$ ) and indirect (cardiovascular disease 10.6\%, infection 8.8\%,embolism $8.8 \%$,cerebrovascular $8 \%$, lung disease $3.7 \%$,addiction $2.7 \%$, autoimmune disease 2.7 ,cancer $1.8 \%$,kidney disease $1.8 \%$ illegal abortion $1.8 \%$ ) .We didn't have any data regarding the neonatal outcomes and so HIV Positive in women.

Among the mothers who died, $73.5 \%$ were 18 to 34 years old, $1.22 \%$ were 35 years old or above and only $4.4 \%$, were less than 18 years of age. Of these, $83.2 \%$ lived in the city and $16.8 \%$ lived in rural areas, but there were significant relationship between age, place of residence, and maternal deaths $(\mathrm{P}$-value $<0.05)$.

The relationship between gestational age and maternal mortality in the two groups were analyzed such that a significant relationship existed between them (P-value $<0.001$ ).Also, according to mean test difference of the number of pregnancy ( 2.41 in the case group and 2 in control group) and the number of abortions and maternal mortality was statistically significant (P-value $<0.005)$.

Results showed significant difference between the underlying disease and death in the control and case groups (P-value $<0.001$ ). Only $49.6 \%$ of the case group and $60.6 \%$ of the control group had access to proper prenatal 
care and this difference was significant (P-value $<0.041$ ). The relationship between mode of delivery and the agent of delivery and maternal mortality were evaluated uand the correlation between them was confirmed, but the difference between the case and control groups in the time may be of the two last pregnancy was not significant (P-value $>0.05)$ (Tables 1,2$)$.

Table 1. Frequency distribution and related factors of maternal mortality in the case and control groups

\begin{tabular}{|c|c|c|c|c|c|}
\hline \multirow{2}{*}{ Variable } & \multirow{2}{*}{ Group } & \multicolumn{2}{|l|}{ Case } & \multicolumn{2}{|l|}{ Control } \\
\hline & & Number & Percent & Number & Percent \\
\hline \multirow[t]{4}{*}{ Gestational age } & $16-24$ & 13 & 11.5 & 6 & 1.5 \\
\hline & $25-28$ & 17 & 15 & 11 & 3.4 \\
\hline & $29-37$ & 29 & 25.7 & 57 & 17.7 \\
\hline & $38-42$ & 54 & 47.8 & 253 & 77.4 \\
\hline \multirow[t]{4}{*}{ Number of pregnancy } & 1 & 33 & 29.2 & 111 & 33.9 \\
\hline & 2 & 89 & 34.5 & 147 & 45.0 \\
\hline & 3 & 19 & 16.8 & 45 & 13.8 \\
\hline & $\leq 4$ & 22 & 19.5 & 24 & 7.3 \\
\hline \multirow[t]{2}{*}{ Number of abortion } & 0 & 82 & 72.6 & 282 & 86.5 \\
\hline & $\leq 1$ & 31 & 27.4 & 45 & 13.5 \\
\hline \multirow[t]{8}{*}{ Underlying disease } & No & 47 & 41.6 & 239 & 73.1 \\
\hline & Cardiac & 17 & 15 & 12 & 3.7 \\
\hline & Diabetes & 7 & 6.2 & 14 & 3.4 \\
\hline & Respiratory & 6 & 5.3 & 10 & 3.1 \\
\hline & Kidney & 6 & 5.3 & 8 & 2.4 \\
\hline & High blood pressure & 10 & 8.8 & 28 & 8.6 \\
\hline & Addiction & 8 & 7.1 & 8 & 2.4 \\
\hline & Other & 12 & 10.6 & 8 & 2.4 \\
\hline \multirow[t]{2}{*}{ Appropriate prenatal care } & Yes & 56 & 49.6 & 198 & 60.6 \\
\hline & No & 57 & 50.4 & 129 & 39.4 \\
\hline \multirow[t]{2}{*}{ Kind of delivery } & Vaginal & 27 & 30 & 160 & 48.9 \\
\hline & Cesarean & 63 & 70 & 167 & 51.1 \\
\hline \multirow[t]{3}{*}{ Delivery agent } & Local midwife & 4 & 4.5 & 3 & 0.9 \\
\hline & Educated midwife & 14 & 14.4 & 83 & 85.6 \\
\hline & Obstetrician & 71 & 79.8 & 241 & 73.7 \\
\hline \multirow[t]{3}{*}{ Time may be between the last pregnancy } & $3<$ & 39 & 48.1 & 104 & 4.44 \\
\hline & $3 \geq$ & 42 & 51.9 & 130 & 55.6 \\
\hline & Total & 81 & 100 & 234 & 100 \\
\hline
\end{tabular}

As shown in Table 2, the most common cause of death is related to preeclampsia and eclampsia (23\%) bleeding (20.4\%) and Illegal abortion (1.8\%). In order to study the effect of various factors on probability of death in pregnancy, logistic regression was used. The results showed that chance of death in pregnant women whose husbands were illiterate or had primary education was 3.8-folds the risk of death in women that their husbands had a high school education or higher, so that $\mathrm{OR}=3.8 \mathrm{CI} 95 \%(1.076-13.546)$.

Also, the chance of death in pregnant women with underlying disease was 5-folds of death risk among women who did not have an underlying disease, such that the OR $=5.03$ CI 95\% $(2.776-9.119)$. The results showed that chance of death in pregnant women who had a vaginal delivery was $0 / 33$ folds the women who had cesarean 
section $0 / 33$, so that $\mathrm{OR}=0.33 \mathrm{CI} 95 \%(0.15-0.73)$, and death risk in women with gestational age 6-28 weeks was $3 / 36$ folds the gestational age of $42-28$ weeks, so that $\mathrm{OR}=3.36 \mathrm{CI} 95 \%$ (1.209-9.341) (Table 3 ).

Table 2. Frequency distribution and percent of maternal mortality by cause of death

\begin{tabular}{lll}
\hline Cause of infection & Number & Percent \\
\hline Preeclampsia - eclampsial & 26 & 23.0 \\
Bleeding & 23 & 20.4 \\
Cardiovascular disease & 12 & 10.6 \\
Infection & 10 & 8.8 \\
Embolism & 10 & 8.8 \\
Cerebrovascular & 9 & 8.0 \\
Lung disease & 5 & 3.7 \\
Anesthesia & 4 & 3.5 \\
Addiction & 3 & 2.7 \\
Autoimmune disease & 3 & 2.7 \\
Cancer, Kidney disease and illegal abortion2 & 6 & 5.4 \\
\hline Total & 113 & 100 \\
\hline
\end{tabular}

1. Preeclampsia is a condition of pregnancy characterized by high blood pressure (hypertension) and protein in the urine (proteinuria) (Farzianpour et al., 2014).

2. Abortion is the ending of pregnancy by removing a fetus or embryo before it can survive outside the uterus (Farzianpour et al., 2014).

Table 3. Logistic regression analysis of variables in the control group

\begin{tabular}{lllllll}
\hline Variables & B & S.E. & P.Value & OR & \multicolumn{2}{c}{$\mathbf{9 5 \%}$ C.I. for } \\
\cline { 5 - 7 } & & & & Upper & Lower \\
\hline Number of pregnancy 1 & -0.681 & 0.604 & 0.260 & 0.506 & 1.655 & 0.155 \\
Number of pregnancy 2 & -0.939 & 0.549 & 0.087 & 0.391 & 1.147 & 0.133 \\
Number of pregnancy 3 & -0.776 & 0.551 & 0.159 & 0.460 & 1.354 & 0.156 \\
Pregnancy age & 1.212 & 0.522 & 0.020 & 3.361 & 9.341 & 1.209 \\
Hospital type of delivery & -0.197 & 0.354 & 0.578 & 0.821 & 1.643 & 0.410 \\
Spouse education 1 & 1.340 & 0.646 & 0.038 & 3.818 & 13.546 & 1.076 \\
Spouse education 2 & 0.607 & 0.390 & 0.119 & 1.836 & 3.941 & 0.855 \\
Spouse education 3 & 0.335 & 0.542 & 0.537 & 1.398 & 4.046 & 0.483 \\
Mother education 2 & -0.209 & 0.380 & 0.583 & 0.812 & 1.709 & 0.385 \\
Number of abortion & 0.322 & 0.406 & 0.428 & 1.379 & 3.056 & 0.623 \\
Infection with underlying disease & 1.616 & 0.303 & 0.000 & 5.032 & 9.119 & 2.776 \\
Delivery agent & 0.457 & 0.506 & 0.367 & 1.580 & 4.262 & 0.585 \\
Intentionality of pregnancy & 0.057 & 0.392 & 0.885 & 1.058 & 2.283 & 0.491 \\
Delivery type & -1.116 & 0.410 & 0.006 & 0.327 & 0.731 & 0.147 \\
Appropriate prenatal care & -0.225 & 0.310 & 0.469 & 0.799 & 1.467 & 0.435 \\
\hline I. & & & & &
\end{tabular}

1. Illiterate, Elementary; 2. Secondary and Diploma; 3.Diploma and Higher.

\section{Discussion}

This study was undertaken to investigate the frequency of maternal mortality and its associated risk factors in 
Tehran from 2008 to 2011. According to the findings, 113 pregnant women in Tehran During this time, with an average of 15.8 deaths per 100 thousand live births have died and the highest maternal mortality ratio in 2009 was equal to 19.1 and the lowest proportion was 13 in 2011 which is the same as the calculated MMR index over the years.

Generally, maternal mortality has declined during these years indicating an improvement in the services provided to the mother. But according to the conducted studies in Sistan-Baluchistan province from 2002 to 2009 , maternal mortality was 82.6 (Ending Preventable Maternal Mortality, 2015); in Hormozgan province from 2005 to 2011, maternal mortality was 39.7 (Ending Preventable Maternal Mortality, 2015); in Kermanshah province from 2001 to 2012, maternal mortality was 25.9 (WHO, 2014); and in Ilam province from 2002 to 2010, maternal mortality was 25.5 per 100 thousand live births (Deadly delivery, 2014) and this shows better situation in Tehran in the field of maternal health as compared to other provinces.

In relation to maternal age and death, the findings showed that $73.5 \%$ of women who died were 18 to 34 years old, while $1.22 \%$ and above were 35 years old and above and only $4.4 \%$ were under 18 years old, but there was no significant difference between the two groups in this regard. In 2011, 77\% of mothers had in Iran who died were 18 to 35 years old, $3 \%$ were under 18 years old and $20 \%$ were over 35 years of age (HUNT et al., 2008). In the study of Agan et al. (2010), the highest percentage of death (65.3) was at the age of 20 to 34 years and 16.8\% were under 18 years (Hernández-Correa, 2010) which is consistent with the present study.

In a study by Golian et al. (2004) in the Kordestan province, no deaths occurred in the age group under 18 years old and the lowest number of maternal death (18.2) was related to 35 years old and above (Evance et al., 2013). But the review of the factors associated with death of pregnant women in America showed that death in women aged 35 years and above were more than other age groups, and the rate of mortality in women over 40 years were 4 times more than women from 30 to 34 years old (Iqbal et al.,2014). Callaghan et al. (2012) showed the death in women of 35 to 39 years old to be 2 times more than death in women of 29 to 25 years old (Abdollahipour et al.,2011).

Given that $90 \%$ of pregnancies in the province were in the age group of 34 to 18 years old (Emami Afshar et al., 2010). It seems that maternal deaths in each age group were a function of the number of pregnancy in the same age group and occurrence of the highest maternal mortality rate in mothers of 18 to 34 years old shows reduction of marriage in the lower age. Also, increasing access to midwifery services and reducing fertility, high-risk pregnancy and increased access to contraceptive methods reduce the risk of unintended pregnancy at high risk age, resulting in the reduction of maternal mortality in this age group.

In the field of urban-rural location, with many more deaths in the city, there was no significant difference between the two groups. According to the statistic in $2011,57 \%$ of mothers who died lived in city and $43 \%$ lived in rural areas (Maternal Health Departmen, 2011). Khajeiyan et al. (2012) study was similar to the present study which did not show significant difference between maternal mortality in urban and rural areas (Maternal Health Department, 2010). The study of Abdollahpour et al. (2011) showed that maternal mortality ratio in rural areas of Ilam was $35.08 \%$ per 100 thousand live births and this ratio was higher than maternal deaths in urban areas (24.75\%) (AbdollahpourPourandokht et al., 2011) .

In studies by Gholami et al. (2008), Arshin Chi (2009), and Zhou et al. (2011), significant differences between maternal deaths in urban and rural regions were also obtained (Gholami Taramsari Mahshid, 2008; Arshin Chi, 2009; Zhou et al., 2011). Lack of significant difference between the two groups in this study could be due to people living in villages around Tehran access to health services and prenatal care.

In relation to gestational age, results showed that most deaths (47.8\%) in the case group occurred in gestational age of 42 to 37 weeks and the difference between gestational age and mortality was statistically significant in both groups (P-value $<0.001$ ) in a study conducted by Mansouri et al. (2006). The highest maternal mortality cases occurred in the third trimester of pregnancy (88.5\%) (Mansouri et al., 2006), which is consistent with the results of this study, because of the increased risk?

The average of pregnancy number in the case group and in control group was, respectively 2.41 and 2 and difference between the two groups was statistically significant (P-value $<0.005$ ) in the study by Abdollahpour et al. (2011), where a significant association between maternal mortality and number of pregnancy was observed. This means that the percentage of the first and fourth pregnancy in the maternal deaths was more than healthy women (Abdollahpour Pourandokht et al., 2011). In a study by Rajaee et al. (2013), first and second pregnancy correlated directly to death (Rajaee et al., 2013).

Research findings by Golian et al. (2004) showed that the highest percentage of people in terms of the number of pregnancies in both case and control groups had 1 to 3 pregnancies $(63.6 \%$ in case group and $81.8 \%$ in control group), and this relationship was significant (Golian et al., 2004). In the study by Mansouri et al. (2005), first 
pregnancy to multiple pregnancy and births are more important risk factor in maternal mortality (Mansouri et al., 2005). According to a study done by the WHO in 2006, abortion or stillbirth deaths is half the 6 weeks after completion of the pregnancy (WHO, 2006).

In the present study, there was a significant relationship between the number of abortions and maternal mortality $(\mathrm{P}$-value $=0.026)$ and $27.3 \%$ in case group and $13.5 \%$ in the control group had a history of one or more abortions, but in the study by Koch et al. (2012), reducing the maternal mortality ratio was not associated with legal abortion (Koch et al., 2012).

About underlying disease, significant differences were found between the two groups and generally smaller number of mothers in the control group was diagnosed of underlying disease. In a research, Abdollahpour et al. (2011) according to this study also observed a significant association between maternal mortality and the underlying disease (Abdollahpour et al., 2011).

Also, according to the military operation care maternal deaths in $2011,71 \%$ of mothers who died had underlying diseases (Alkema, 2014). Studies show that some women had underlying condition and are pregnant and this show the lack of knowing, low health literacy, neglect or lack of education.

Access to prenatal care is important, but only $49.6 \%$ of the case group and $60.6 \%$ of the control group had access to proper prenatal care and the difference was statistically significant (P-value $<0.041$ ) in study by Abdollahpour et al. (2011), where there was reverse relationship between prenatal care and their death, if the quality of prenatal care among pregnant women and healthy feet were different (Abdollahpour et a., 2011). Also in 2011, only 65\% of maternal deaths in the country had received proper care to gestational age (Alkema, 2014).

Study by Mohammadinia et al. (2013), Maharlouei et al. (2012), Agan et al. (2013) and Khan et al. (2013) also confirmed the results of this study (Mohammadinia et al., 2013; Maharlouei et al., 2012; Agan et al., 2013; Khan et al., 2013). It seems that in addition to access to care, prenatal care is one of the reasons for the differences in the two groups caused by their attitude and level information.

Concerning style of delivery, most mothers in the case group (70\%) and control group (51.1\%) were delivered by cesarean and there was a significant relationship between mode of delivery and deaths. In a study by Maharlouei et al. (2012), 61.8\% of maternal deaths occurred after cesarean delivery and the difference between the methods was statistically significant (Maharlouei et al., 2012).

In a study by Khajehian et al. (2011), 60\% of women who died were delivered by cesarean section (Khajehian et al., 2011), which was not consistent with the present study. While in a study by Mohammadinia et al. (2013) and Rajaee et al. (2013), most women had died after delivery and this difference was significant (Mohammadinia et al.,2013; Rajaee et al.,2013) which is not consistent with the present study. In a study by Haseli et al. (2013), no significant relationship was also found between death and labor practices (Haseli et al., 2013).

The researcher believed that the reasons for maternal death were as a result of the increase in caesarean section, paying more for cesarean delivery than vaginal delivery, preventing vaginal delivery by midwives in hospitals, especially in Tehran, mothers tending to cesarean delivery, lack of oversight on the cesarean by the department of health and insurance network of the country. Also, the percentage of death in caesarean sections performed over the death could be due to the nature of high-risk pregnancy.

The relationship between childbirth and maternal mortality factors were also statistically significant $(\mathrm{P}$-value $=$ 0.015 ) and more deliveries in both groups were done by educated gynecologists and midwives. Haseli et al. (2013) studied on the death of pregnant women in the province of Ilam did not show any significant relationship between agent and cause of death [20]. But results of the study by Mohammadinia et al. (2013) were consistent with the present study (Mohammadinia et al., 2013). Also, according to the state of maternal deaths, $76 \%$ of mothers who died in 2011 were delivered under gynecologists supervision and $20 \%$ of them were delivered under midwives supervision in the hospital; a total of $96 \%$ of deliveries were done by people who have a university education and these mothers have a safe delivery standards, however, finally died (Alkema, 2014) Possible cause of mortality of delivery done by gynecologists and obstetricians were unsafe pregnancy and childbirth.

In the field of last time may be between two pregnancies, more or less than three years difference between groups was not significant. In a study done by Maharlouie et al. (2012) in 76.3\% of deaths, the distance between the last two pregnancies was more than 2 years (Maharlouie et al., 2012). In a study by Khajehian et al. (2011), only $7.5 \%$ of mothers who died had pregnancies distance less than 3 years (Khajehian et al., 2011).

Also country index showed the distance of pregnancy less than 3 years in 2011 to be 17\% (Alkema, 2014) while in the study by Mohammadinia et al. (2013) in Sistan-Baluchistan province, the last distance between the two pregnancies was $68.8 \%$ of the women who died 2 years or less (Mohammadinia et al., 2013). Dead pregnant 
women in Tehran province were in good condition by the observance of pregnancy distance and this was not a major cause of maternal mortality because the use of modern methods of contraception, reside in the city and free access to family planning services.

According to findings, the most common causes of death were preeclampsia and eclampsia (23\%) and bleeding (20.4\%). Statistics released by the Ministry of Health and Medical Education in 2011 showed the most common causes of maternal death include bleeding (27\%), preeclampsia $(15 \%)$, heart disease $(10 \%)$, amniotic fluid embolism (8\%), infection, and underlying diseases (7\% each) (Alkema, 2014).

In a study by Mohammadinia et al. (2013) in Sistan and Baluchistan, the main causes of maternal mortality were bleeding (39.5\%) and preeclampsia and eclampsia (23.4\%) (Mohammadinia et al., 2013). Also, studies of Rajaee et al. (2013), Haseli et al. (2013), Khajehian et al. (2011) and Maharlouie et al.,2013; (2012) observed bleeding as the main cause of the death (Mohammadinia et al., 2013; Rajaee et al., 2013; Haseli et al., 2013; Khajehian et al., 2011).

Another study by Agan et al. (2010) in Calabar hospital in Nigeria, bleeding was the main reason for maternal death (32.23\%) and blood pressure disorders was next in rank (Agan et al., 2010). In the study of the global causes of maternal mortality by WHO (2014), the main cause of maternal mortality from 2003 to 2009 were bleeding and hypertensive disorders (WHO, 2014).But in the study by Gumanga et al. (2011) in a medical education hospital in Ghana, the leading causes of maternal mortality were infection (19.8\%), hypertensive disorders (18.6\%), and bleeding (15.8\%) (Gumanga et al., 2011).

In most studies, bleeding is the main cause of maternal death, but the main cause of maternal death in the present study is not bleeding and this could be raised to keep mothers in hospital for more precise control and also access to blood transfusions when necessary. In this study, infection was not as the first three causes of maternal death, because the proper use of antibiotics and higher levels of health has an important role in this issue.

\section{Conclusion}

These study findings suggest that maternal mortality has been declining over the years, due to the factors identified in maternal mortality, such as gestational age, number of pregnancy, number of abortions, the underlying disease, access to prenatal care, labor and operating practices. It is recommended that strategies like improving the quality of hospital services in the field of obstetric emergencies, improving the quality and coverage of prenatal care, safe delivery by trained individuals to encourage mothers, abstaining from performing caesarean sections, according to the role of education and knowledge in improving maternal health, especially in rural areas using the appropriate technology, training, identification of high risk pregnancies and referrals to specialized centers, efficient and experienced personnel and speeding up the process of education services by increasing equipment such as blood products used to reduce the mortality rate of pregnant women.

Also, due to constraints, such as lack of some records, lack of access to families to complete information and in some cases illegible answers in the case, it is recommended that similar studies should be done in this field of prospect in the future to evaluate other factors, such as, socio-economic status.

\section{Acknowledgements}

This article is a part of a MPH thesis entitled "Frequency and Risk Factors Associated with Mortality in Pregnant Women in Tehran-Iran" that has been supported by Tehran University of Medical Sciences, Faculty of Health. The authors thank all those who have helped researchers at all stages of the project.

\section{Limitations of the Study}

Incompleteness of records insufficient cooperation and coordination of hospital personnel that this problem has been resolved

\section{Competing Interests Statement}

The authors declare that there is no conflict of interests regarding the publication of this paper.

\section{References}

Abdollahipour, P., Babaei, M., \& Ghasemi, Y. (2011). Causes of Maternal Mortality in Pregnant Women in Urban and Rural Areas of Ilam, Iran. Journal of Health System Research, 7(6), 1278-1287. [In Persian]

Abdollahpour, P., Babaei, M., \& Ghasemi, Y. (2011). Investigate The Causes of Maternal Deaths during Childbirth in Rural and Urban Areas of Ilam. Journal of Research in the Health System, 7(6), 1-9.

Abdolmohammad, K., Anaraki, A., Motamed, N., Ghaedmohammadi, Z., \& Dornan, M. (201). Factors Associated With Maternal Deaths In Boshehr In 1999-2007. Journal of Mother and Baby, 11-18.

Agan, T. U., \& Archibong, E. L. (2010).Trends in maternal mortality at the university of calabar teaching 
hospital, nigeria,1999-2009. INT J WOMEN HEALTH, 2249-254.

Alkema, L., Chou, D., Gemmill, A., Hogan, D., Mathers, C., Mills, S., \& Moller, A. B. (2014). Trends in Maternal Mortality: 1990 to 2013. Estimates by WHO, UNICEF, UNFPA, the World Bank and the United Nations Population Division. World Health Organization 2014.

Arshin Chi, M. (2009). Demographic Study of Maternal Mortality in Iran Today (Master's Thesis, Azad University Central Tehran Branch, Tehran.152-154). [In Persian]

Callaghan, W. M. (2012). Overview of maternal mortality in united states. Seminars in perinatology, 36(1), 2-6. http://dx.doi.org/10.1053/j.semperi.2011.09.002

Chang, J., Elam-Evans, L., \& Cynthia, J. (2003). Morbidity and mortality weekly report, CDC, 52, 1-2.

Deadly delivery. (2011). The maternal health care crisis in the USA one year update. Amnesty international. 2011.

Emami Afshar, N., Jalilvand, P., Delaware, B., RadpUyan, L., Azemikhah, A., \& Valafar, S. H. (2010). Maternal Death Surveillance (pp. 14-30). Tehran: Tandis Publications. [In Persian]

Ending Preventable Maternal Mortality. USAID Maternal Health Vision for Action. 2014.

Ending Preventable Maternal Mortality. USAID Maternal Health Vision for Action, Evidence for Strategic Approaches.2015.

Evance, I., Godfrey, M., Honorati, M., \& Kathleen, K. (2013). Causes and Risk Factors for Maternal Mortality in Rural Tanzania Case of Rufiji Health and Demographic Surveillance Site (HDSS). African Journal of Reproductive Health, 17(3), 119-130.

Farzianpour, F., Ramezani, K. H., Rahimi, F., \& Changizi. (2014). Assessing Demographic Factors Related to Maternal Mortality in Tehran Province, Iran from 2008 to 2011. (MPH Thesis, School of Public Health, Tehran University of Medical Sciences, 2014).

Gelyani, S. H., \& Holakoyi, K. (2005).Factors affecting maternal mortality in the Kordestan province in the1999-2003 years.Journal of life, 21, 47-54. [In Persian]

Gholami-Taramsari, M. (2008). The Ten Causes of Death of Pregnant Women in Kohgiluyeh Boyer Ahmad. Journal of Science and Health, 3(2), 33-37

Gholami-Taramsari, M. (2008).Ten-Year Evaluation of Maternal Mortalities in Kohgiluyeh and Boyerahmad Province.Journal of Knowledge \& Health, 3(2), 33-37. [In Persian]

Golian, T., Shahnaz, H., Kourosh, Z., \& Mojdeh. (2004). Factors Affecting Maternal Mortality In Kurdistan In 1998-2002. Life Magazine, 21(138), 47-54

Gumanga, S. K., \&Kolbila, D. Z. (2011).Trends in maternal mortality in tamale teaching hospital, Ghana.Gana med j, 45(3), 105-110.

Haseli, A., Ghiasia, M., Seififard, F., \& Ebrahimzadeh, M. (2014).The Study of Frequency and Effective Factors on Maternal Mortality in Ilam Province during 2002-2010. Scientific Journal of Ilam University of Medical Sciences, 22(7), 39-46.

Hernández-Correa, J. C. (2010). Maternal Mortality and Risk Factors at the Community Level. Department of Economics.

Hosseini, M. (2006). Epidemiology of Nurses. Boshra Publications: Tehran. [In Persian]

Hunt, P. B., \& De Mesquita, J. (2008). Reducing Maternal Mortality.The contribution of the right to the highest attainable standard of health. UNFPA.

Imami, A. N., Jalilvand, P., Delaware, B., RadpouyanLaleh, A. A., \& Shahrzad, V. (2010). Care of Maternal Mortality (pp. 14-30). Tehran, Tandis Publications.

Iqbal, K., Shaheen, F., \& Begum, A. (2014). Risk Factors of Maternal Mortality. Journal of Rawalpindi Medical College (JRMC), 18(1), 136- 38.

Jamshidpour, M., Izadi, N., Najafi, F., Khamoushi, F., Roustaei Shirdel, A., \&Jalili, K. (2015). Maternal mortality rate and causes in Kermanshah province (2004-2012). Journal of Kermanshah University of medical sciences, 18(7), 409- 415. [In Persian]

Khajeiyan, A., Anaraki, A., Motamed, N., Ghaed Muhammadi, Z., \& Melki, D. (2012). Factors associated with maternal deaths in the Boshehr province in 2001- 2008. Journal of maternal and newborn health, 11-18. 
Khan, N., \& Pardhan, M. R. (2013). Identifying factors associated with maternal deaths in Jharkhand, India: A Verbal autopsy study. Journal of Health, Population, and Nutrition, 31(2), 262-271. http://dx.doi.org/10.3329/jhpn.v31i2.16391

Koch, E., Thorp, J., Bravo, M., Gatica, S., Romero, C. X., Aguilera, H., \& Ahlers, I. (2012).Women's Education Level, Maternal Health Facilities, Abortion Legislation and Maternal Deaths: A Natural Experiment in Chile from 1957 to 2007. PLoS ONE, 7(5), e36613. http://dx.doi.org/10.1371/journal.pone.0036613

Maharlouei, N., Zakeri, Z., Mazloomi, E., \&Lankarani, K. (2012). Maternal mortality rate in fars province: Trends and associated factors in a community - based survay. Archivesc of Iranian medicine, 15(1), 14-17.

Mansouri, A. (2005). Investigate The Causes Of Maternal Mortality And Its Determinants In Cases Referred To Khorasan Forensic Medicine In The Years 1998-2004. Journal of Forensic Medicine, 7(37), 28-31.

Mansuri, A. Hejazi, A., \& Badieyan Musavi, N. (2006). Investigate the causes of maternal mortality and its determinants in the cases referred to forensic medicine center in Khorasan. Journal of Forensic Medicine, 37(11), 28-31. [In Persian]

Maternal Health Department of Family Health and Population. Report On the Performance and Achievements of Maternal Death Care, Ministry Of Health and Medical Education, 2011, pp. 3-8

Maternal Health Department of Family Health and Population. Report On the Performance and Achievements of Maternal Death Care, Ministry Of Health and Medical Education, 2010, pp. 1-12

Maternal Health Department, Bureau of Family Health and Population. Report on the performance and achievements of maternal death Care, Ministry of Health and Medical Education. 2011, 3-8. [In Persian]

Maternal Health Department, Bureau of Family Health and Population. Report on the performance and achievements of maternal death Care, Ministry of Health and Medical Education. 2010, 1-12. [In Persian]

Maternal Health Department, Bureau of Family Health and Population. Report on the performance and achievements of maternal death Care, Ministry of Health and Medical Education. 2006.[In Persian]

Miller, S., \& Belizán, J. M. (2015).The true cost of maternal death: individual tragedy impacts family, community and nations. Reproductive Health, 12, 56.

Mohammadinia, N., Samii Zadeh Toosi, T., Rezaei, M. A., \& Rostaei, F. (2013). Prevalence and Influencing Factors of Death for Pregnant Women in the Province of Sistan and Baluchestan in the Years 2002-2009. Journal of Iranian Women, Infertility and Gynecology, 16(44), 28-34. [In Persian]

Office of Family Health and Population, IMES, Ministry Of Health and Medical Education. (2005).

Rajaei, M., Zare, Sh., Dadipoor, S., Falahi, S., Rajaei, F., Pourahmad Goorbandi, F., Moradi, S., \& Mobarak Abadi, A. (2014). Determining the frequency of maternal mortality causes in Hormozgan Province during the years 2005-2011. Journal of Iranian Women, Infertility and Gynecology, 16(87), 9 -14. [In Persian]

Rajaei, M., Zare, Sh., Dadpour, S., Fallahi, S., Rajaei, F., Pourahmad Gourbandi, F., ... Mobarak Abadi, A. (2013). The Frequency and The Influencing Factors On Death Of Pregnant Women In Hormozgan In 2005-2011.Women, Midwife And Sterility Journal In Iran, 16(87), 9-14.

Ronsmans, C., \& Graham, W. J. (2006). Maternal mortality: who, when, where, and why. Lancet, 368 , 1189-2000. http://dx.doi.org/10.1016/S0140-6736(06)69380-X

Say, L., Chou, D., Gemmill, A., Tunçalp,Ö., Moller, A.B., Daniels, J., ... Leontine, A. (2014). Global causes of maternal death: A WHO systematic analysis. Lancet Glob Health, 2, 323-33. http://dx.doi.org/10.1016/S2214-109X(14)70227-X

World Health Organization. (2014). Maternal mortality. Department of Reproductive Health and Research World Health Organization.

World Health Organization. (2015). Strategies toward ending preventable maternal mortality (EPMM).

Zhou, Y. Y., Zhu, J., Wang, Y. P., Dai, L., Li, X. H., Li, M. R., Li, Q., \& Liang, J. (2011). Trends of maternal mortality ratio during 1996-2010 in China. Zhonghua Yu Fang Yi Xue Za Zhi, 45(10), 934-9.

\section{Copyrights}

Copyright for this article is retained by the author(s), with first publication rights granted to the journal.

This is an open-access article distributed under the terms and conditions of the Creative Commons Attribution license (http://creativecommons.org/licenses/by/3.0/). 